
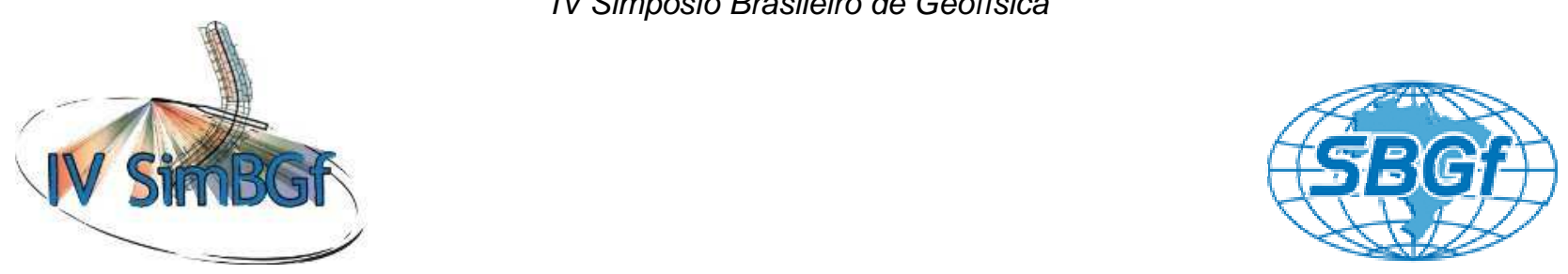

\title{
A comparison of robust and non-robust marine magnetotelluric data models in Santos Basin, Brazil.
}

Vinicius R. Pinto ${ }^{1 *}$, Sérgio L. Fontes ${ }^{1}$, Emin. U. Ulugergerli²; 1 - Observatório Nacional/MCT, Brazil; 2 Çanakkale Onsekiz Mart University, Turkey.

Copyright 2010, SBGf - Sociedade Brasileira de Geofísica

Este texto foi preparado para a apresentação no IV Simpósio Brasileiro de Geofísica, Brasília, 14 a 17 de novembro de 2010. Seu conteúdo foi revisado pelo Comitê Técnico do IV SimBGt, mas não necessariamente representa a opinião da SBGf ou de seus associados. É proibida a reprodução total ou parcial deste material para propósitos comerciais sem prévia autorização da SBGf.

\section{Abstract}

In this work we present a comparison made using both robust and non-robust processing of marine magnetotelluric data from the southeast coast of Brazil, most precisely in the Santos basin. The marine magnetotelluric data can be affected by many problems such as noise distortion and difficulties related to the logistics in marine acquisition. The first problem is a classical and delicate issue that depends of filtering and processing stages to avoid these effects. We have used the technique presented by Egbert, et al., (1986) to perform a robust processing of magnetotelluric data and that way trying to attenuate the effect of the outliers on the data. The first results of this procedure and a comparison with others non-robust models is shown.

\section{Introduction}

Magnetotellurics (MT) is a geophysical method for investigating the subsurface structure resistivity of the earth (Hoversten, et. al., 1998). The method can be applied for different targets at land and water environments. The last one is especially problematic because the presence of seawater acting as high-pass filter dropping periods bigger than $1 \mathrm{~s}$. Traditionally the MT was thought as a technique for investigating the mantle structure using periods of $10^{3}$ to $10^{5} \mathrm{~s}$. To be useful for mapping subsurface of ocean floor at depths relevant to oil exploration, the measurements need to be made at periods between 1 and $1000 \mathrm{~s}$. This can be accomplished by using induction coils for magnetic field measures and electric field amplifiers especially developed for marine applications (Constable, et. al., 1998). Although even with a high effort to proceed a marine survey the data acquired are not free of noise distortions as, e.g., the motional noise generated by wave motion in shallow waters. The region of interest is the Santos basin located in the southeast coast of Brazil (Figure 1).
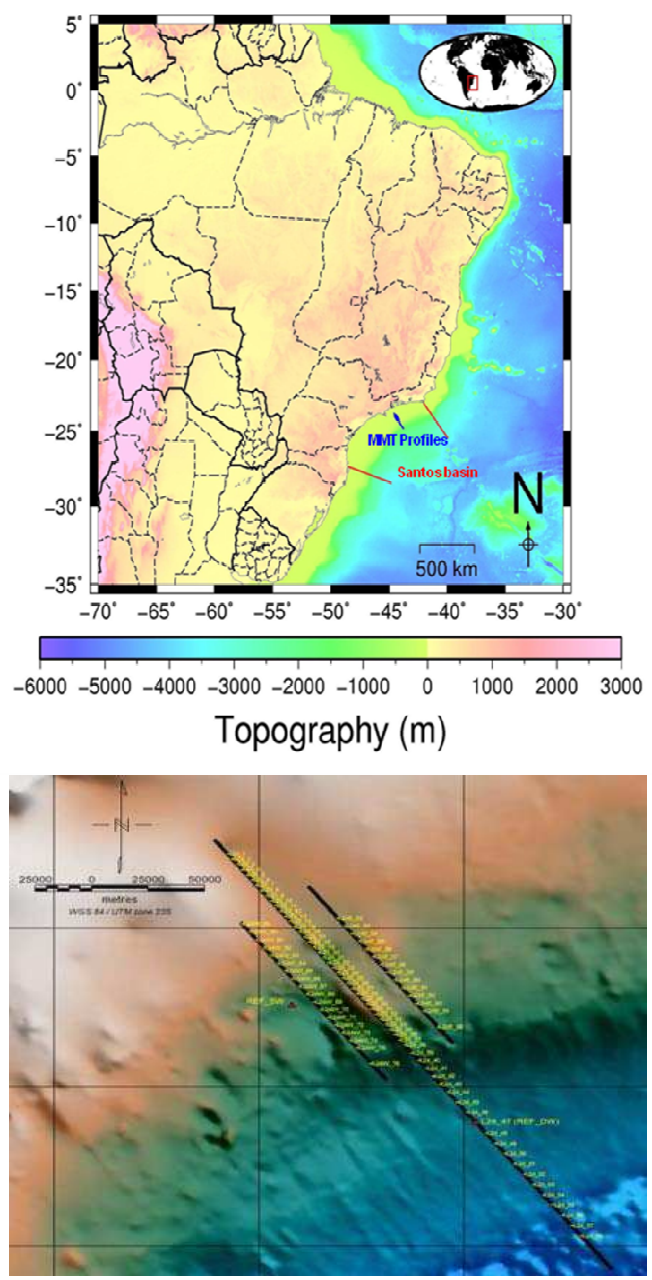

Figure 1: Map showing the Santos basin and location of the MMT profiles. Below is a zoom with the three profiles. 
The basin has approximately $350,000 \mathrm{~km}^{2}$ and a water depth varying from about 50 to $1500 \mathrm{~m}$. The basin has potentially pre-salt reservoirs and studies are justified by recent oil and gas discoveries made by industry at the region. The magnetotelluric survey generated a total of 96 stations divided into three parallel profiles crossing the region at the NWSE direction. For this work we have only analyzed the central profile (P-02 line) with 56 stations and approximately $160 \mathrm{~km}$ extension. The orientation of this line is based on gravity anomaly map that exhibits an approximately NE-SW structural trend (Fontes, et al., 2009) (Figure 2).

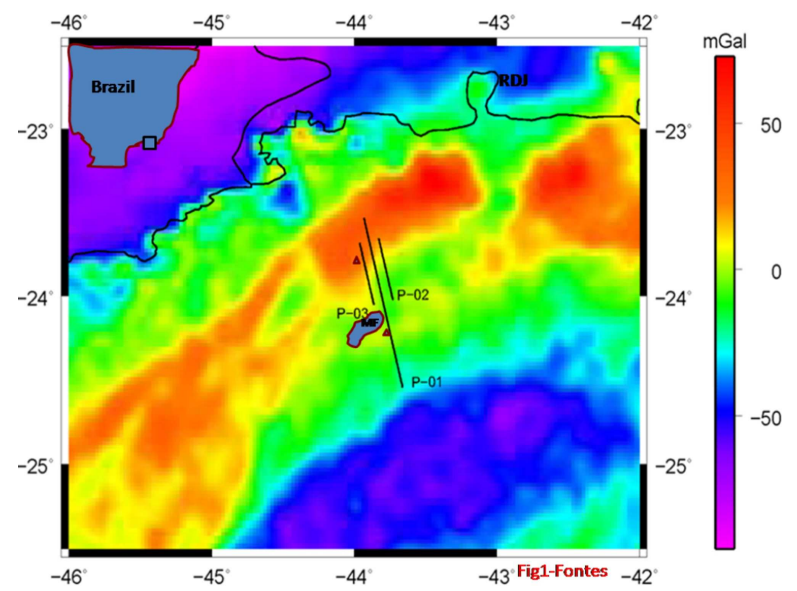

Figure 2: Gravity anomaly map showing the twodimensional behavior of the region. This feature confirms the choice of orientation of survey.

In this work we have applied a robust processing to avoid these undesirable effects and we are also going to present a comparison with non-robust (least square) models. To judge by the appearance of the resistivity and phase curves reached we are going to have very good quality results. With these robust processed curves we can get improved models with less uncertainty.

\section{Methodology}

The magnetotelluric method can be resumed in solving the particular relationship

$$
\vec{E}(\omega)=\vec{Z}(\omega) \bullet \vec{H}(\omega)
$$

where $\mathbf{E}$ and $\mathbf{H}$ are the electric and magnetic fields respectively and $\mathbf{Z}$ is the impedance tensor. However this mathematical problem does not hold exactly, because there are measurement errors and because the plane wave source field assumption is, at best, only approximately true. The estimation of these parameters has been discussed exhaustively along years and many others solutions have been proposed.

The solution of this problem is not satisfactory in many cases due to the non-stationary behavior of the fields. In addition, as the relation (1) has errors related, the estimation of the impedance tensor components becomes essentially a statistical problem. The least square approach is not satisfactory in many cases. The robust processing is a reasonable procedure for avoiding the outliers and thus preventing the dramatic effect of bad data points on the distribution. Here is pretended to apply the robust estimation for magnetotelluric transfer functions proposed by Egbert and Booker. This technique consists in minimizing the misfit function (like in Least Squares) but not allowing few bad points (outliers) to dominate the estimates. Actually, in attempting to avoid these few bad points' effects is necessary to submit the data to Groom \& Bailey (1989) philosophy that assumes a 2D regional model and 3D shallow distortions are superposed and removed in the procedure.

The robust method is based on a method called 'Regression M-estimate' (Huber, 1981). Basically, the objective is to minimize the following function

$$
\sum_{i} \rho\left(\frac{E_{i}-Z H_{i}}{\sigma}\right)
$$

with $\rho$ being the loss function and defined by

$$
\rho(r)= \begin{cases}\frac{r^{2}}{2} & |r|<r_{0} \\ r_{0}|r|-\frac{r_{0}^{2}}{2} & |r| \geq r_{0}\end{cases}
$$

$\sigma$ is the standard deviation and $r$, the squared residual. Note that the equation (3) in conjunction with (2) signifies the least squares approach for small residuals and the robust approach for larger residuals. In other words it switches between $L_{1}$ and $L_{2}$ minimization. Thus we have a parameter that provides information about how permissive the technique is and this one normally takes the value of 1.5 (for Gaussian errors). Finally, the key point of the method is performing an automatic robust analysis scheme which for the systematic increase of errors with increasing power and which 
automatically downweights source contaminated outliers.

\section{Results and discussions}

In this section we compare the results of this methodology and previous results of application of least squares processing. The technique presented here of robust estimation of impedance tensor components was completely successful. We firstly used a $0.064 \mathrm{~s}$ sampling rate of raw data and take 800 segments with approximately 4 minutes time window each one. The raw data were low pass filtered and decimated by a factor of 4 to produce more than 2 days time window total. An example of time series typically registered in the survey is shown in figure 3.

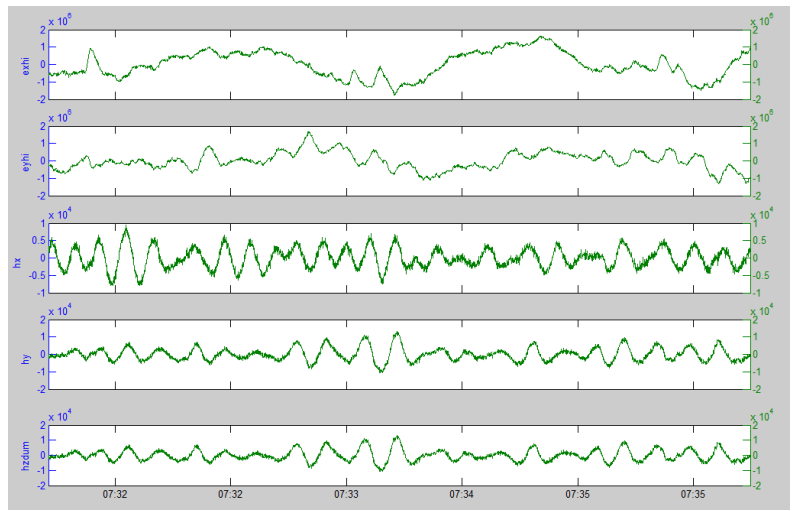

Figure 3: Time series typically registered by the marine receivers. These data are correspondent to station number 1 located in shallow waters.

Some of the results of classical least square processing can be seen in figure 4. As we can see there are great amount of noisy data especially at middle frequencies. These effects are present in both resistivity and phase and such noise causes much damage to the data and it leads to not accurate resistivity models. An example of a model created using these dataset of Santos basin is presented in figure 5 . The model was calculated using a routine developed by Rodi and Mackie (2001) which finds regularized solutions based on Tikhonov Regularization (Tikhonov and Arsenin, 1977) to the two-dimensional inverse problem for MT data using the method of nonlinear conjugate gradients. The correct position of the structures in the model is intimately related of the quality of the rho and phase curves, it is clear why is so important to get the curves as best as possible. In comparison, we show the resistivity and phase distributions achieved with the robust processing (Figure 6).

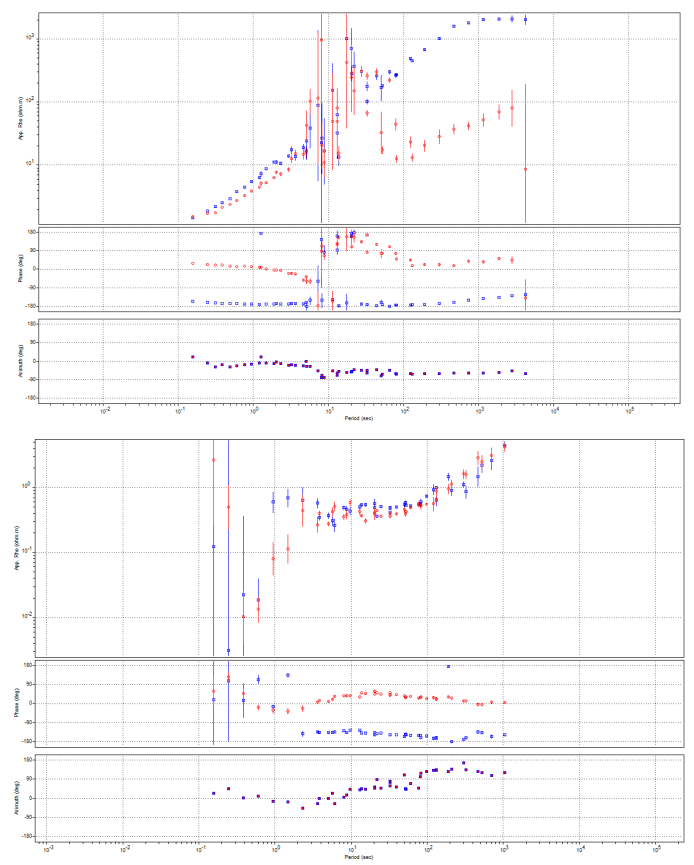

Figure 4: Resistivity and phase curves for stations 10 and 54 of central profile. The noise is most evident at middle frequencies.

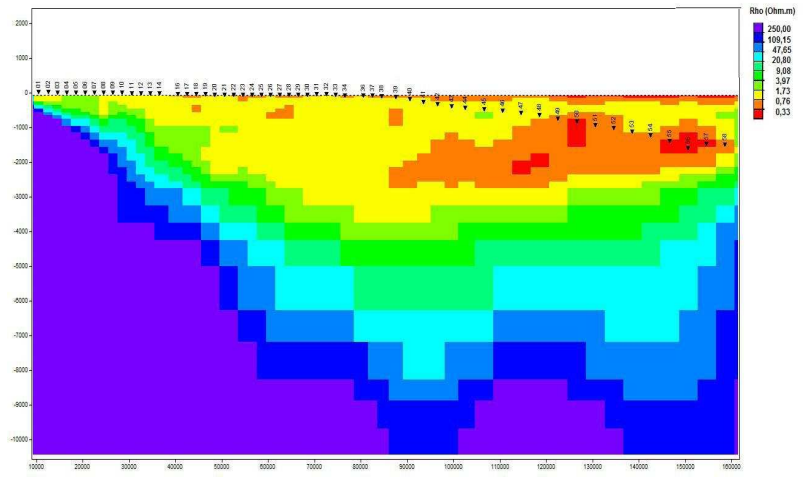

Figure 5: Geo-electrical model of central profile obtained from 2D-inversion of marine MT data (Pinto, et. al., 2009).

\section{Conclusions and future works}

The results presented here are a first approach regarding robust processing using these marine 
magnetotelluric data. Lugão, et. al. (2008) showed the first preliminary results of this dataset. Evidently this paper is a proposal of application of Egbert's robust technique, the results achieved until the moment are shown in figure 4 . Our results come to become possible comparisons between them and all least square approaches. If we analyze the difference on quality and fit between figures 4 and 6 , is plausible to expect very good models. We are going to present these models in the presentation of the IV Symposium of the Brazilian Geophysical Society. For the future we hope can perform a joint inversion following the methodology adopted by Gallardo, et. al. (2010) using these magnetotelluric robust processed, seismic, gravity and magnetic data available in Santos basin.
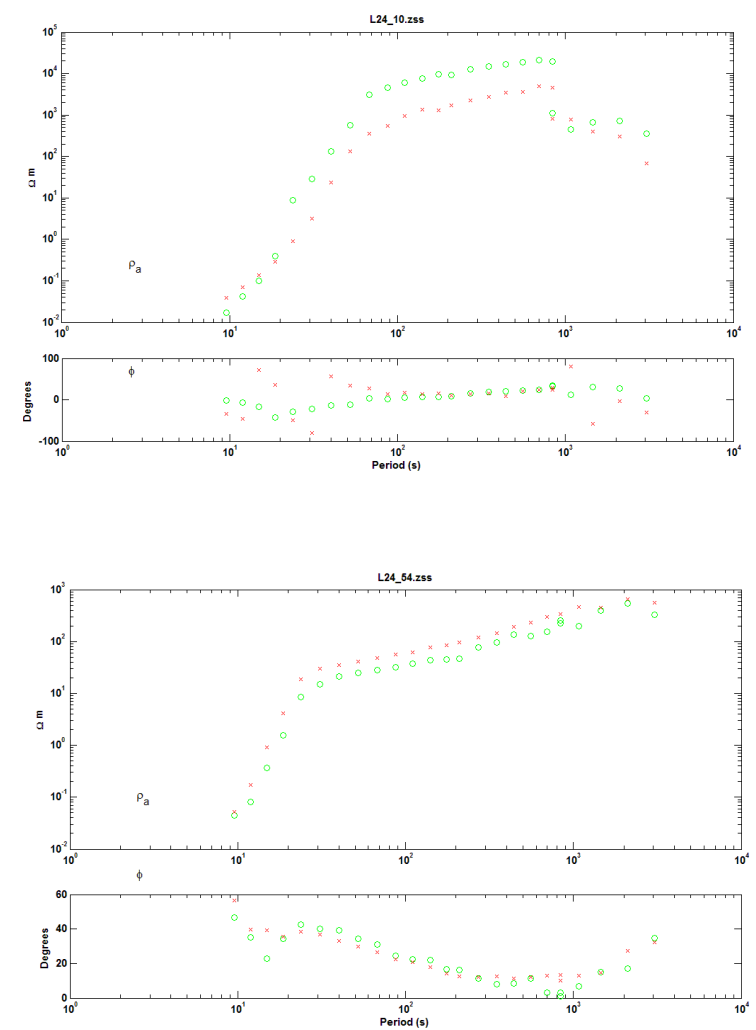

Figure 6: Examples of resistivity and phase curves for stations 10 and 54 respectively. As we can see these results are better fits than in figure 4 .

\section{Acknowledgements}

The authors would like to thank Petrobras, CAPES and Observatorio Nacional/MCT for technical and financial supporting for this project.

\section{References}

Constable, S. C., et al., 1998. Marine magnetotellurics for petroleum exploration, Part I: A sea-floor equipment system. Geophysics, vol. 63, no. 3, pp. 816-825.

Egbert, G. D. \& Booker, J. R., 1986. Robust estimation of geomagnetic transfer functions. Geophys. J. R. astr. Soc. 87, 173-194.

Fontes, S. L., Lugão, P. P., Meju, M. A., Pinto, V. R., Flexor, J. M., Ulugergerli, E. U., La Terra, E. F., Gallardo, L. A. and Rijo, L., 2009. Marine magnetotelluric (MMT) mapping of basement and salt bodies in the Santos Basin of Brazil. First Break, 27, May, 37-41.

Gallardo, L. A., Fontes, S. L., Meju, M., Lugão, P. P. and Buonora, M. P., 2010. Joint cross-gradient inversion of offshore seismic reflection, MT, gravity and magnetic profiles over a petroliferous prospect in Santos basin, Brazil. IAGA WG 1.2 on Electromagnetic Induction in the Earth 20th Workshop Abstract Giza, Egypt, September 18-24.

Groom, W. G. and Bailey, R. C., 1989. Decomposition of Magnetotelluric Impedance Tensors in the Presence of Local ThreeDimensional Galvanic Distortion. Journal of Geophysical Research, Vol. 94, No. B2, pp. 19131925.

Hoversten, G. M., Morrison, H. F. and Constable, S. C., 1998. Marine magnetotellurics for petroleum exploration, part II: Numerical analysis of subsalt resolution. Geophysics, 63, no. 3, 826-840.

Huber, P. J., 1981. Robust Statistics, Wiley, New York.

Lugão, P. P., Fontes, S. L., La Terra, E. F., Zerilli, A., Labruzzo, T. and Buonora. M. P., 2008. First application of marine magnetotellurics improves depth imaging in the Santos basin, Brazil. 70th EAGE Conference \& Exhibition, 9-12 June, Rome, Italy.

Pinto, V. R., 2009. O Método Magnetotelúrico Marinho (MMT) na Exploração de Hidrocarbonetos. Msc. Thesis, Observatório Nacional/MCT, Rio de Janeiro, Brasil.

Rodi, W. and Mackie, R. L., 2001. Nonlinear conjugate gradients algorithm for 2D magnetotelluric inversion. Geophysics, vol. 66, no. 1, 174-187.

Tikhonov, A. N. and Arsenin, V. Y., 1977. Solutions of ill posed problems. W. H. Winston, California, USA, 258 pp. 